\title{
Mechanisms of action of Ig preparations: immunomodulatory and anti-inflammatory effects
}

\author{
Andrea Matucci ${ }^{1}{ }^{* \dagger}$, Enrico Maggi ${ }^{2 \dagger}$ and Alessandra Vultaggio ${ }^{1 \dagger}$ \\ 1 Immunoallergology Unit, Department of Biomedicine, Policlinico di Careggi, Florence, Italy \\ 2 Immunology and Cellular Therapies Unit, Department of Biomedicine, Centre Denothe, Policlinico di Careggi, University of Florence, Florence, Italy
}

\author{
Edited by: \\ Isabella Quinti, Sapienza University of \\ Rome, Italy \\ Reviewed by: \\ Elham Hossny, Ain Shams University, \\ Egypt \\ Mark Ballow, University at Buffalo \\ SUNY, USA \\ ${ }^{*}$ Correspondence: \\ Andrea Matucci, Immunoallergology \\ Unit, Department of Biomedicine, \\ Policlinico di Careggi, Viale Morgagni, \\ 85, Firenze 50134, Italy \\ e-mail: andrea.matucci@unifi.it \\ ${ }^{\dagger}$ Andrea Matucci, Enrico Maggi and \\ Alessandra Vultaggio have \\ contributed equally to this work.
}

Primary immunodeficiency (PID) disorders that predispose patients to recurrent infections require immunoglobulin $(\mathrm{lg})$ replacement therapy. Ig replacement therapy has been stated as beneficial, although the optimal lgG trough level to be maintained over time in order to minimize infectious risk has not been established. The most common route of administration of I g has been intravenously, although there are different options, one of them being the subcutaneous route. Ig replacement therapy has been a life-saving treatment for patients suffering from primary and secondary antibody immunodeficiency. The key role of regular $\mathrm{lg}$ replacement in patients with antibody deficiencies is related to the ability to provide specific antibodies that could not be produced by these patients as demonstrated by the reduction of severe infections such as meningitis and pneumonia. The therapeutic benefits of Ig may also be due to an active role in various anti-inflammatory and immunomodulatory activities, which may complicate the clinical picture of PID. Anti-inflammatory activities are seen more generally when intravenous $\mathrm{Ig}$ is administered at high dose. The immunomodulatory and anti-inflammatory activities are important not only in the treatment of autoimmune diseases but also in patients suffering from immunodeficiency.

Keywords: immunoglobulin, immunodeficiency, immunoregulation of Ig, Ig replacement therapy, antibody defect

\section{INTRODUCTION}

Primary immunodeficiency (PID) disorders that predispose patients to recurrent respiratory, skin, and gastrointestinal infections, require immunoglobulin (Ig) replacement therapy. Common variable immunodeficiency disease (CVID) is one of the most frequent PID characterized by decreased serum levels of all Ig isotypes and recurrent bacterial infections encompassing a heterogeneous group of diseases whose unifying feature is hypogammaglobulinemia (1). The etiopathogenesis of CVID has not been yet fully elucidated. Major progress toward elucidating CVID has been achieved with the identification of defects not only in B-cells, which are directly responsible for antibody production, but also in other immune cells implicated in the generation of an effective humoral response, including antigen-presenting cells (APC) and, in a significant proportion of these patients, helper T cells (24). Overall, the disorder is characterized by a defective antibody production by B lymphocytes. Although the number of B-cells may be normal, patients with CVID show extremely decreased serum IgG, IgA, and, occasionally, IgM concentrations. The treatment of choice for CVID patients is replacement Ig therapy. A common route of administration of Ig has been intravenously (IVIg) although today there are different options, one of them being the subcutaneous route (SCIg). Ig replacement therapy has been a life-saving treatment for patients suffering from primary and secondary antibody immunodeficiencies, in fact, a recent published meta analysis of clinical trials in PID quantitatively confirms that trough IgG levels directly impact clinical outcomes (5). However, the optimal IgG trough level to be maintained over time in order to minimize infectious risk, has not been established and probably it should be individualized (6-8). The key role of regular Ig replacement in patients with antibody deficiencies is related to the ability to provide specific antibodies that could not be produced by these patients as demonstrated by the reduction of severe infections such as meningitis and pneumonia (9). The therapeutic benefits of Ig may also be due to an active role in various anti-inflammatory and immunomodulatory activities. In fact, clinical and immunopathological aspects of the association between CVID and autoimmune or inflammatory disorders have been extensively reported in a number of patients $(10,11)$. On the other hands, Ig preparations other than antibodies to superantigens and pathogens also contain numerous soluble proteins with biologic activity such as cytokines, chemokines, soluble cytokine receptors, and receptor antagonists. In fact, since they were first administered to patients with antibody deficiency disorders over 50 years ago, human intravenous Ig preparations have been used successfully to treat a rapidly increasing number of autoimmune and inflammatory disorders, among which are a series of cutaneous autoimmune and inflammatory diseases (12). Despite the identification of protective, immunomodulatory, and anti-inflammatory activities in various diseases, the benefits of Ig are not easily explained and probably depend by several mechanisms. Anti-inflammatory activities are seen more generally when intravenous Ig is administered at high dose. The immunomodulatory and anti-inflammatory activities are important not only in the treatment of autoimmune diseases but also in patients suffering from immunodeficiency. In this article, the protective and immunoregulatory mechanisms are summarized. 


\section{IMMUNOGLOBULIN PREPARATION}

The major component of IVIg and SCIg preparations is the IgG fraction, which is pooled from human plasma of several thousands of donors using a procedure that varies somewhat between manufacturers, but results in a product that is a relatively pure concentrate of intact monomeric IgG, with a half-life of 3 weeks, and with small amounts of IgA and IgM. IgG subclasses (IgG1, IgG2, IgG3, and IgG4) in IVIg and SCIg products have a distribution similar to that found in normal human plasma. IgG aggregates are virtually absent from the majority of Ig preparations even if up to $1-10 \%$ of $\operatorname{IgG}$ can be found in dimeric form in most of IVIg preparations. The processes of purification have the potential to adversely affect the final quality and biological activity of IVIG/SCIG in terms of efficacy and safety (13). Natural antibodies and autoantibodies are prominent in commercial preparations. A wide range of specificities have been identified within Ig preparations including idiotypes of Ig itself, T cell receptor, cell surface molecules such as CD4, CD5, Fas, BAFF, cytokines, and cytokine receptors, such as IL-1; IL-6, tumor necrosis factor (TNF)- $\alpha$, chemokine receptors, molecules such as sialic acid binding Ig-like lectin (Siglec)-8 and -9 or major histocompatibility complex (MHC) molecules; natural autoantibodies of IgG isotype directed against the human Fc $\gamma$ RIII (CD16) and Fc $\gamma$ RII (CD32) (14-16).

\section{MECHANISMS OF IVIg IN THE CORRECTION OF HUMORAL DEFECTS}

The underlying mechanisms of therapeutic effects of IVIg/SCIg in PID are not completely understood, the major aim is to prevent life-threatening bacterial or viral infections (Figure 1). IVIg/SCIg act mainly as a reconstitution therapy, providing patients with pathogen-specific antibodies able to protect from infectious. The unique structure of the Ig molecule ensures the large repertoire of specificities of the antibodies. To maintain the polyclonal nature of the antibody repertoire that is normally present in serum of healthy subjects naturally exposed to microbial agents or submitted to vaccines is a crucial step during the preparation of commercial Ig. Considering that IVIg preparations are generated from adults who have been vaccinated and have encountered a multitude of pathogenic microorganisms, serum IgG can comprise more than 100 million unique specificities. The clinical and functional activities can be distinguished by the infused amounts. In fact, a monthly Ig dosage of at least $400 \mathrm{mg} / \mathrm{kg}$ body weight is recommended and is most often sufficient as replacement therapy (17). The activities of Ig molecules present in IVIg/SCIg preparations, such as bactericidal effect through complement system activation, viral neutralization, inactivation of toxins, and opsonization, are crucial for the induction of an effective immune response against several microorganisms and their toxic products. As known, IgG antibodies include two functional portions as the $\mathrm{F}\left(\mathrm{ab}^{\prime}\right)$ fragment, which is responsible for antigen recognition, and the fragment crystallizable $(\mathrm{Fc})$, crucial for activating the mechanisms of immunity by interacting with $\mathrm{Fc} \gamma$ receptors on B-cells and other cells of the innate immune system belonging to the phagocytic system. The Fc fragment is also crucial for the activation of complement and for the clearance of microorganisms (18). B-cells from several CVID patients seem to be not intrinsically defective as they express CD40 and proliferate significantly upon anti-CD40 stimulation. Interestingly, IVIg at "replacement dose" $(10 \mathrm{mg} / \mathrm{ml})$ are able to interact with B-cells, also inducing significantly higher proliferation of B-cells than anti-B cell receptor (BCR) stimulation alone. In addition, IVIg replacement is able to induce Ig synthesis ex novo by B-cells (19). Therefore, IVIg therapy, at least in some CVID, is able to modulate B cell functions and it is a passive transfer of antibodies. As previously mentioned, PID are a heterogeneous group of disorders that affect distinct components of the innate

\begin{tabular}{|c|c|}
\hline Replacement therapy & Anti-inflammatory therapy \\
\hline $\begin{array}{l}\text { Fab-dependent activities } \\
\text { Pathogen-spedific antibodies } \\
\text { Neutralization of pathogen } \\
\text { Inactivation of toxins } \\
\text { Opsonization } \\
\text { Induction of } \mathrm{B} \text { cells proliferation and Ig synthesis } \\
\text { Increase of CD4+T lymphocytes number } \\
\text { Increase of myeloid dendritic cell activation }\end{array}$ & $\begin{array}{l}\text { Fab-dependent activities } \\
\text { Neutralization of autoantibodies } \\
\text { Neutralization of pro-inflammatory cytokines } \\
\text { Blocking of activated Complement components } \\
\text { Blocking adhesion moleoules } \\
\text { Interferenoe with idiotypic/anti-indiotypic network } \\
\text { Modulation of antibody production } \\
\text { Modulation of maturation/ function of dendritic cells }\end{array}$ \\
\hline $\begin{array}{l}\text { Fc-dependent activities } \\
\text { Activation of phagocytic cells (FcyR-dependent) } \\
\text { Complement activation } \\
\text { Clearance of microrganisms }\end{array}$ & $\begin{array}{l}\text { Fc-dependent activities } \\
\text { Blocking of the FcRn (increased autoantibody dearance) } \\
\text { Blocking of activating FcyR } \\
\text { Increase of inhibitory FcyRllb expression } \\
\text { Immunomodulatory effects of sialylated IgG } \\
\text { Increase of Treg œell }\end{array}$ \\
\hline
\end{tabular}

FIGURE 1 | Mechanisms of action of IVIg in PID 
and adaptive immune system. Defects not only in B-cells, which are directly responsible for antibody production, but also in other immune cells such as APC and T helper (Th) cells, represent the molecular basis of CVID $(20,21)$. It has been shown that in CVID patients the humoral defects may be associated with immunological abnormalities of $\mathrm{T}$ cell compartment and myeloid dendritic cells ( $\mathrm{mDC})$, characterized by low counts of CD4+ T cells, high expression of HLA-DR and CD38 (also on CD8+ T cells), suppressed number of $\mathrm{mDC}$, highly positive for CD80 and CD83. Several of these cellular perturbations are partially corrected by the treatment with IVIg. In fact, the introduction of therapy may lead to CD4 $+\mathrm{T}$ cell recovery and decline in CD8 $+\mathrm{T}$ cells and $\mathrm{mDC}$ activation. These effects are likely sustained by an improved immune control of infections due to humoral reconstitution (22).

\section{MECHANISMS OF ACTION OF IVIg IN COMORBIDITY OF PID}

The use of IVIg has been firmly established for the treatment of a wide variety of autoimmune and inflammatory diseases, due to their immune-regulatory and anti-inflammatory effects (Figure 1). Some of these autoimmune diseases may be a comorbidity of PID, especially CVID, thus sustaining an additional role, beyond the antibody replacement, for IVIg in the treatment of immunodeficiencies. For example, the immunoregulatory functions of IVIg in PID patients explain the therapeutic effects showed in autoimmune hemolytic anemia and/or immunothrobocitopenia, probably by blocking the clearance of opsonized target cells or by suppressing antibody-dependent cell-mediated cytotoxicity. This potential was first revealed when IVIg, used to treat a patient with antibody deficiency, were able to restore platelets count when concomitant thrombocytopenia occurred (23). The way in which IVIg exert their immunomodulatory effects remain unclear, with many pathways, probably mutually non-exclusive, in the innate and adaptive immune systems being potentially targeted. At least a percentage of immune modulatory effects of IVIg are dependent upon the interaction between the Fc portion with the Fcy receptors expressed on the surface of cells as macrophages, B-cells, natural killer (NK) cells, plasma cells, and platelets (18). For example, as previously mentioned, it has been clearly demonstrated that Fc fragment of IgG can be sufficient to ameliorate immunemediated thrombocytopenia in humans (24), by suppressing the phagocytosis of platelets via an Fc-dependent mechanism instead of preventing autoantibodies from binding to cells (25). Studies performed both in mice and humans confirmed that IVIg infusion is able to inhibit the mononuclear phagocytic system, usually activated by immune complexes through activating of low-affinity Fc $\gamma$ Rs (26). However, there is no direct proof that IVIg block the binding of immune complexes to Fc $\gamma$ Rs. The Fc portion of Ig not only impacts the function of activating Fc receptors but also increase the expression of inhibitory Fc $\gamma$ RIIB on macrophages (27). Recent studies in animal models of idiopathic thrombocytopenic purpura suggest that IVIg, increasing the expression of the $\mathrm{Fc} \gamma$ receptor IIB, may reset the threshold for cell activation by immune complexes $(18,25)$. In other words, IVIg should be able to shift the Fc $\gamma$ R-dependent balance of activating and inhibitory signals even more toward cell inhibition of innate immune effector cells.
A mechanism implicated in immune-regulatory function of IVIg preparation is also the effect on the balance between pro- and anti-inflammatory cytokines. To this effect, antibodies to IL- 1 and TNF- $\alpha$ have been identified in addition to a down-regulation of such cytokines (28). Furthermore, IVIg induce anti-inflammatory cytokines such as IL-10, TGF- $\beta$, and IL-1ra from monocytes/macrophages $(28,29)$. In our hands, in IVIgtreated PID patients the raising of IL-10 after administration of therapy was not observed in those with associated granulomatous lung disease, thus suggesting the lack of the induction of regulatory cytokines in such subgroup of patients. Dendritic cells represent an important source of pro-inflammatory and antiinflammatory cytokines and a modulation of cytokine secretion has been shown, characterized by a decrease of IL-12 production and enhanced secretion of IL-10 has been described. DC maturation, activation, and survival are also targeted by IVIg, thus affecting the overall APC activity with subsequent inhibition of adaptive $T$ cell response, including autoreactive cells (30). This latter effect is of potential relevance considering the beneficial action in autoimmune conditions.

Dendritic cells are professional APC with superior capacity to present both MHC-restricted and CD1-restricted antigens. DCs may adapt their CD1 antigen presentation machinery according to signals in the microenvironment. A role for IgG in regulating the expression of CD1 molecules in human DCs has been shown in in vitro experiments. In particular, it has been found that the level of exposure to IgG regulates the CD1 expression profile during DC differentiation, and that this is mediated by Fc $\gamma$ RIIa. This in turn determines whether the DCs will be biased toward activation of CD1d-restricted regulatory NKT cells or T cells specific for lipid antigens presented by CD1a, CD1b, and CD1c (31). Furthermore, results obtained from patients with CVID indicate that mDCs express elevated levels of CD1a and CD1b in the presence of low levels of IgG in vivo, and that this aberrant expression pattern is normalized after IVIg therapy (32). These findings are important for our understanding of diseases associated with Ig deficiencies and their treatment with IVIg.

Concerning the IVIg effects on apoptosis, triggered by the interactions between CD95 (Fas) and its ligand (CD95L, FasL), controversial data are present in literature and probably both agonist and antagonist properties may be attributed to IVIg. In CVID, an increased expression of Fas on CD3 + T cells has been demonstrated and a further increase was shown after IVIg therapy (33). In the context of autoimmune disease as comorbidity of PID, the process could be important in that specific harmful T cells may be deleted through apoptosis.

The complement system is a first line of defense against invading microorganisms, but if its activation occurs under inappropriate circumstances, this system may be not beneficial leading to complement-mediated disorders characterized by cell lysis and tissue damage. Ig plays an intriguing role in complement and regulation. IVIg preparation contain pathogen-specific antibodies and autoantibodies able to activate the effector system, but on the other hand, the rest of the circulating Ig pool (mainly of IgG and IgM isotype) have the capacity to attenuate damaging effects of activated complement fragments. This latter effect seems to be 
related to a scavenger action toward complement fragments that is dependent on a low-affinity interaction between the fragment in question and various Ig regions ( $\mathrm{Fc}$ binding to $\mathrm{C} 3 \mathrm{~b} / \mathrm{C} 4 \mathrm{~b}$; $\mathrm{Fab}$ binding to $\mathrm{C} 3 \mathrm{a} / \mathrm{C} 5 \mathrm{a})$. Such immunocomplexes are then removed by the reticuloendothelial system (34).

Even if many immunoregulatory effects have been ascribed to IVIg, it remains unclear why high doses of IVIg are required to obtain this activity. Some insights were gained when the role of IgG glycosylation was addressed in animal models. Deglycosylated Ig appeared to be unable to provide anti-inflammatory protections, although glycan was found in only 1-3\% of IgG preparation (35). Sialylated Fc present in low amount in IVIg binds to SIGN-R1 on macrophages leading to an increased expression of the inhibitory Fc $\gamma$ RIIB receptors and decreased expression of Fc $\gamma$ Rs. The overall result is an anti-inflammatory and anti-phagocytic effect. The key role of the terminal sialic acid residues is confirmed by the role of the molecules CD22 and CD33, also called SIGLEC, which are expressed by B-cells and cells of innate immune system (36, 37). Their capacity to trigger cell inactivation is related to the activation of intracellular immunoreceptor tyrosine-based inhibitor motifs (ITIMs). Of note, while the importance of Fc sialylation has been clearly shown in animal models, its role in humans should be better evaluated, and important species differences may probably exist.

\section{CONCLUSION}

Immunoglobulin therapy is a consistently evolving practice that provides life-saving protection to patients with PID, particularly with antibody deficiency as well as in patients with other immunemediated diseases. Taking into account the growing demand of Ig preparations not only for PID patients but also for subjects suffering from chronic immune-mediated diseases, more clinical trials will be required as well as basic research able to improve the knowledge on the mechanisms of action of IVIg.

\section{REFERENCES}

1. Cunningham-Rundles C. How I treat common variable immunodeficiency. Blood (2010) 116:7-15. doi:10.1182/blood-2010-01-254417

2. Spickett GP. Current perspectives on common variable immunodeficiency (CVID). Clin Exp Allergy (2001) 31:536-42. doi:10.1046/j.1365-2222.2001. 01117.x

3. Buckley RH. Primary immunodeficiency diseases due to defects in lymphocytes. N Engl J Med (2000) 343:1313-24. doi:10.1056/NEJM200011023431806

4. Capitani N, Ariani F, Amedei A, Pezzicoli A, Matucci A, Vultaggio A, et al. Vav1 haploinsufficiency in a common variable immunodeficiency patient with defective T-cell function. Int J Immunopathol Pharmacol (2012) 25:811-7.

5. Orange JS, Grossman WJ, Navickis RJ, Wilkes MM. Impact of trough IgG on pneumonia incidence in primary immunodeficiency: a metaanalysis of clinical studies. Clin Immunol (2010) 137:21-30. doi:10.1016/j.clim. 2010.06.012

6. Quinti I, Soresina A, Guerra A, Rondelli R, Spadaro G, Agostini C, et al. Effectiveness of immunoglobulin replacement therapy on clinical outcome in patients with primary antibody deficiencies: results from a multicenter prospective cohort study. J Clin Immunol (2011) 31:315-22. doi:10.1007/s10875-0119511-0

7. Gathmann B, Mahlaoui N; CEREDIH, Gérard L, Oksenhendler E, Warnatz K, et al. Clinical picture and treatment of 2212 patients with common variable immunodeficiency. J Allergy Clin Immunol (2014) 134:116-26. doi:10.1016/j. jaci.2013.12.1077

8. Orange JS, Hossny EM, Weiler CR, Ballow M, Berger M, Bonilla FA, et al. Use of intravenous immunoglobulin in human disease: a review of evidence by members of the Primary Immunodeficiency Committee of the American Academy of
Allergy, Asthma and Immunology. J Allergy Clin Immunol (2006) 117:S525-53. doi:10.1016/j.jaci.2006.01.015

9. Lucas M, Lee M, Lortan J, Lopez-Granados E, Misbah S, Chapel H. Infection outcomes in patients with common variable immunodeficiency disorders: relationship to immunoglobulin therapy over 22 years. J Allergy Clin Immunol (2010) 125:1354-60. doi:10.1016/j.jaci.2010.02.040

10. Cunninghan-Rundles C, Bodian C. Common variable immunodeficiency: clinical and immunological features of 248 patients. Clin Immunol (1999) 92:34-48. doi:10.1006/clim.1999.4725

11. Mackay IR, Leskovsek NV, Rose NR. The odd couple: a fresh look at autoimmunity and immunodeficiency. J Autoimmun (2010) 35:199-205. doi:10.1016/ j.jaut.2010.06.008

12. Gelfand EW. Intrevenous immune globulin in autoimmune and inflammatory diseases. N Engl J Med (2012) 367:2015-25. doi:10.1056/NEJMra1009433

13. Martin TD. IGIV: contents, properties, and methods of industrial production evolving closer to a more physiologic product. Int Immunopharmacol (2006) 6:517-22. doi:10.1016/j.intimp.2005.11.005

14. Seite J, Shoenfeld Y, Youinou P, Hillions S. What is the content of the magic draft IVIG? Autoimmune Rev (2008) 7:435-9. doi:10.1016/j.autrev.2008.04.012

15. Ravindranath MH, Terasaki PI, Maehara CY, Jucaud V, Kawakita S, Pham T, et al. IgG purified from human sera mirrors IVIg's HLA reactivity and recognizes one's own HLA types, but may be masked by Fab CDR peptide in the native sera. Clin Exp Immunol (2014). doi:10.1111/cei.12450

16. Bouhlal H, Martinvalet D, Teillaud JL, Fridman C, Kazatchkine MD, Bayry J, et al. Natural autoantibodies to $\mathrm{Fc} \gamma$ receptors in intravenous immunoglobulins. J Clin Immunol (2014) 34:S4-11. doi:10.1007/s10875-014-0019-2

17. Kaveri SV, Maddur MS, Hegde P, Lacroix-Desmazes S, Bayry J. Intravenous immunoglobulins in immunodeficiencies: more than mere replacement therapy. Clin Exp Immunol (2011) 164:2-5. doi:10.1111/j.1365-2249.2011.04387.x

18. Samuelsson A, Towers TL, Ravetch JV. Anti-inflammatory activity of IVIG mediated through the inhibitory Fc receptor. Science (2001) 291:484-6. doi:10.1126/ science.291.5503.484

19. Bayry J, Fournier EM, Maddur MS, Vani J, Wootla B, Siberil S, et al. Intravenous immunoglobulin induces proliferation and immunoglobulin synthesis form B cells of patients with common variable immunodeficiency: a mechanism underlying the beneficial effect of IVIg in primary immunodeficiencies. $J$ Autoimmunity (2011) 36:9-15. doi:10.1016/j.jaut.2010.09.006

20. Park MA, Li JT, Hagan JB, Maddox DE, Abraham RS. Common variable immunodeficiency: a new look at an old disease. Lancet (2008) 372:489-502. doi:10.1016/S0140-6736(08)61199-X

21. Capitani N, Amedei A, Rossi Paccani S, Matucci A, Vultaggio A, Del Prete GF, et al. Impaired Th2 response in Vav1-deficient common variable immunodeficiency patients with T-cell defects. J Allergy Clin Immunol (2010) 126:671-5. doi:10.1016/j.jaci.2010.05.033

22. Paquin-Proulx D, Santos BA, Carvalho KI, Toledo-Barros M, Barreto de Oliveira AK, Kokron CM, et al. IVIg immune reconstitution treatment alleviates the state of persistent immune activation and suppressed CD4 T cell counts in CVID. PLoS One (2013) 8:e75199. doi:10.1371/journal.pone.0075199

23. Imbach P, Barandun S, D’Apuzzo V, Baumgartner C, Hirt A, Morell A, et al. Highdose intravenous gammaglobulin for idiopathic thrombocytopenic purpura in childhood. Lancet (1981) 1:1228-31. doi:10.1016/S0140-6736(81)92400-4

24. Debre M, Bonnet MC, Fridman WH, Carosella E, Philippe N, Reinert P, et al. Infusion of $\mathrm{Fc} g$ fragments for treatment of children with acute immune thrombocytopenic purpura. Lancet (1993) 342:945-9. doi:10.1016/0140-6736(93) 92000-J

25. Crown AR, Song S, Semple JW, Freedman J, Lazarus AH. IVIg inhibits reticuluendhotelial system function and ameliorates murine passive-immune thrombocytopenia independent of anti-idiotype reactivity. Br J Haematol (2001) 115:679-86. doi:10.1046/j.1365-2141.2001.03136.x

26. Siragam V, Brinc D, Crow AR, Song S, Freedman J, Lazarus AH. Can antibodies with specificity for soluble antigens mimic the therapeutic effects of intravenous IgG in the treatment of autoimmune disease? J Clin Invest (2005) 11:155-60. doi:10.1172/JCI200522753

27. Kaneko Y, Nimmerjahn F, Madaio MP, Ravetch JV. Pathology and protection in nephrotoxic nephritis is determined by selective engagement of specific Fc receptors. J Exp Med (2006) 203:789-97. doi:10.1084/jem.20051900

28. Kazatchkine MD, Kaveri SV. Immunomodulation of autoimmune and inflammatory diseases with intravenous immune globulin. N Engl J Med (2001) 345:747-55. doi:10.1056/NEJMra993360 
29. Reinhold D, Perlov E, Schrecke K, Kekow J, Brune T, Sailer M. Increased blood concentration of TGF-beta isoforms after treatment with intravenous immunoglobulins (i.v.IG) in patients with multiple sclerosis. J Neuroimmunol (2004) 152:191-4. doi:10.1016/j.jneuroim.2004.03.018

30. Bayry J, Lacroix-Desmazes S, Carbonneil C, Misra N, Donkova V, Pashov A, et al. Inhibition of maturation and function of dendritic cells by intravenous immunoglobulin. Blood (2003) 101:758-65. doi:10.1182/blood-2002-05-1447

31. Smed-Sörensen A, Moll M, Cheng TY, Loré K, Norlin AC, Perbeck L, et al. IgG regulates the CD1 expression profile and lipid antigen-presenting function in human dendritic cells via FcgammaRIIa. Blood (2008) 111:5037-46. doi:10.1182/blood-2007-07-099549

32. Paquin-Proulx D, Santos BA, Carvalho KI, Toledo-Barros M, Oliveira AK, Kokron CM, et al. Dysregulated CD1 profile in myeloid dendritic cells in CVID patients is normalized by IVIg treatment. Blood (2013) 121:4963-4. doi:10.1182/blood-2013-04-499442

33. Artac H, Kara R, Reisli I. In vivo modulation of expression of Fas and CD25 by intravenous immunoglobulin in common variable immunodeficiency. Clin Exp Med (2010) 10:27-31. doi:10.1007/s10238-009-0061-1

34. Basta M. Ambivalent effect of immunoglobulins on the complement system. Mol Immunol (2008) 45:4073-9. doi:10.1016/j.molimm.2008.07.012

35. Kaneko Y, Nimmerjahn F, Ravetch JV. Anti-inflammatory activity of immunoglobulin G resulting from Fc sialylation. Science (2006) 313:670-3. doi:10.1126/science. 1129594
36. Pillai S, Netravali IA, Cariappa A, Mattoo H. Siglec and immunoregulation. Ann Rev Immunol (2012) 30:357-92. doi:10.1146/annurev-immunol-020711075018

37. Crocker PR, Redelinghuys P. Siglec as positive and negative regulators of the immune system. Bioch Soc Trans (2008) 36:1467-71. doi:10.1042/BST0361467

Conflict of Interest Statement: The authors declare that the research was conducted in the absence of any commercial or financial relationships that could be construed as a potential conflict of interest.

Received: 16 October 2014; accepted: 23 December 2014; published online: 12 January 2015 .

Citation: Matucci A, Maggi E and Vultaggio A (2015) Mechanisms of action of Ig preparations: immunomodulatory and anti-inflammatory effects. Front. Immunol. 5:690. doi: $10.3389 /$ fimmu.2014.00690

This article was submitted to Primary Immunodeficiencies, a section of the journal Frontiers in Immunology.

Copyright (C) 2015 Matucci, Maggi and Vultaggio. This is an open-access article distributed under the terms of the Creative Commons Attribution License (CC BY). The use, distribution or reproduction in other forums is permitted, provided the original author(s) or licensor are credited and that the original publication in this journal is cited, in accordance with accepted academic practice. No use, distribution or reproduction is permitted which does not comply with these terms. 